\title{
Analisis Nilai Noise dari Citra Pesawat CT-Scan pada Beberapa Rekonstruksi Kernel dengan Variasi Slice Thickness
}

\author{
Almuslimiati $^{1, *}$, Dian Milvita $^{1}$, Heru Prasetio $^{2}$ \\ * ${ }^{1}$ Laboratorium Fisika Nuklir, Jurusan Fisika, FMIPA, Universitas Andalas \\ Kampus Unand, Limau Manis, Padang, 25163 \\ ${ }^{2}$ PTKMR BATAN, Jalan Lebak Bulus Raya No. 49, Jakarta 12440 \\ *almuslimiatii@gmail.com
}

\begin{abstract}
ABSTRAK
Telah dilakukan penelitian tentang analisis nilai noise dari citra pesawat CT-Scan pada beberapa rekonstruksi kernel dengan variasi slice thickness. Penelitian dilakukan dengan menggunakan fantom sebagai bahan pengganti pasien. Penelitian ini bertujuan untuk mengetahui pengaruh penggunaan rekonstruksi kernel terhadap nilai noise. Nilai noise ysng didapatkan dibandingkan dengan batas toleransi yang diizinkan oleh BAPETEN. Slice thickness terbaik akan ditentukan dari masing-masing rekonstruksi yang digunakan. Penelitian dilakukan pada arus $250 \mathrm{mAs}$ dan tegangan $120 \mathrm{kV}$ dengan menggunakan rekonstruksi kernel standar, lung, soft, edge, bone dan chest serta variasi slice thickness dari $1 \mathrm{~mm}-10$ mm. Hasil analisis menunjukkan bahwa perbedaan rekonstruksi kernel yang digunakan memberikan pengaruh berupa peningkatan nilai noise. Nilai noise yang didapatkan masih dalam batas toleransi yang diizinkan oleh BAPETEN. Slice thickness yang paling baik adalah dengan ketebalan $6 \mathrm{~mm}$, karena pada ketebalan ini dihasilkan nilai noise yang paling sedikit. Penggunaan slice thickness yang tidak terlalu tebal akan membuat citra menghasilkan detail-detail gambar yang tinggi dan sebaliknya, untuk itu perlu adanya optimasi penggunaan slice thickness agar bagian tubuh yang menjadi objek pemeriksaan dapat didiagnosis dengan baik.

Kata kunci : fantom, noise, rekonstruksi kernel, slice thickness
\end{abstract}

\section{ABSTRACT}

This research has been conducted on the analysis of noise values of CT-Scan images on some kernel reconstruction with slice thickness variations. The study was conducted using phantom as a substitute for patients. This research aims to determine the influence of the use of some kernel reconstruction on noise value. The noise value obtained is compared to the tolerance limit allowed by BAPETEN. The best slice thickness will be determined from each reconstruction used. The study was conducted on a current of 250 $m A s$ and a voltage of $120 \mathrm{kV}$ using kernel reconstruction : standard, lung, soft, edge, bone and chest, and variations in slice thickness from $1 \mathrm{~mm}-10 \mathrm{~mm}$. The results of the analysis show that the difference on kernel reconstruction used cause an increase in the value of noise. The noise value obtained is still within the tolerance limit allowed by BAPETEN. The best slice thickness is with a thickness of 6 mm because at this thickness the least noise value is produced. The use of slice thickness that is not too thick will make the image produce high image resolution and otherwise, for that it is necessary to optimize the use of slice thickness so that the part of body that is the object of examination can be diagnosed properly. Keywords: phantom, noise, kernel reconstruction, slice thickness

\section{PENDAHULUAN}

Aplikasi teknologi nuklir semakin berkembang dalam berbagai aspek kehidupan, salah satunya dalam bidang kesehatan dibagian radiodiagnostik. Radiodiagnostik merupakan salah satu cabang ilmu radiologi yang menggunakan pencitraan untuk mendiagnosis penyakit dengan memanfaatkan radiasi pengion. Salah satu sumber radiasi pengion yang digunakan dalam bidang radiodiagnostik berasal dari pesawat sinar-X yang memiliki daya tembus yang sangat besar, sehingga mampu menembus bahan yang dilaluinya (Akhadi, 2000).

CT-Scan merupakan suatu sistem pencitraan medis yang cukup kompleks sehingga terdapat resiko terjadinya mis-aligment, kesalahan kalibrasi, dan kegagalan fungsi sistem pembangkit dan deteksi sinar-X. Pesawat CT-Scan memerlukan program quality control (QC) untuk menjamin kualitas citra $C T$-Scan dengan tetep menjaga dosis agar berada di bawah batas yang diizinkan (AAPM, 2002).

Salah satu program QC pada pemakaian pesawat $C T$-Scan adalah uji nilai noise pada berbagai posisi fantom. QC dilakukan dengan menggunakan fantom sebagai bahan pengganti pasien. Sebagian besar bahan penyusun fantom adalah air, air direkomendasikan sebagai bahan untuk menentukan CT Number karena penyusun jaringan lunak pada tubuh manusia merupakan 
air lebih dari 90\%. Selain itu untuk kegiatan penelitian International Atomic Energy Agency (IAEA) menyarankan penggunaan fantom sebagai bahan pengganti pasien. Hal ini bertujuan agar pengukuran saat penelitian bisa dilakukan berulang-ulang, sehingga nilai yang didapatkan akan semakin akurat.

Noise menggambarkan penurunan resolusi kontras suatu citra pesawat CT-Scan, Nilai noise dihitung pada daerah Region of Interest (ROI). Noise pada citra pesawat CT-Scan bisa diketahui dari nilai standar deviasi ROI maksimum dengan ROI minimum. CT Number dapat dinyatakan dalam Hounsfield Unit (HU) pada suatu material yang sama sesuai dengan standar yang sudah ditetapkan (AAPM, 2013).

Menurut perka Badan Pengawas Tenaga Nuklir (BAPETEN) no.2 tahun 2018 tentang uji kesesuaian pesawat sinar-X radiologi diagnostik dan intervensional, batas toleransi nilai noise yang diperbolehkan adalah $\leq 2 \mathrm{HU}$. Faktor yang mempengaruhi nilai standar deviasi hasil citra pesawat CT-Scan meliputi ukuran objek, faktor eksposi (arus, tegangan dan waktu rotasi), Field Of View (FOV), pitch, rekonstruksi matriks, slice thickness, dan rekonstruksi kernel. Slice thickness adalah tebalnya irisan atau potongan citra dari objek yang diperiksa. Rekonstruksi kernel adalah persamaan matematika yang dikonvulsikan pada data-data hasil pengukuran yang digunakan untuk merekontruksi gambar dan menghilangkan blurring (Seeram, 2016).

Hediana (2015) telah melakukan penelitian tentang pengukuran nilai noise dengan variasi slice thickness, hasil yang diperoleh yaitu bahwa nilai noise semakin berkurang dengan penambahan slice thicknes. Anam (2015) telah melakukan penelitian tentang reduksi noise pada citra CT-Scan hasil rekonstruksi metode filtered back-projection (FBP), hasil yang diperoleh yaitu citra hasil rekonstruksi memiliki noise yang tergantung jenis rekonstruksi yang digunakan.

Penelitian tentang nilai noise dengan variasi rekonstruksi kernel perlu dilakukan agar pengaruh rekonstruksi kernel dengan variasi slice thickness terhadap nilai noise pada hasil citra pesawat $C T$-Scan bisa diketahui, serta nilai yang didapatkan akan dibandingkan dengan standar perka BAPETEN No.2 tahun 2018 dan slice thickness terbaik dari masing-masing rekonstruksi yang digunakan dapat ditentukan. Citra yang dihasilkan pada saat pemeriksaan langsung pada pasien harus dalam keadaan baik, sehingga citra yang dihasilkan dapat didiagnosis dengan baik. Ketika citra yang dihasilkan dalam keadaan sulit untuk didiagnosis yang disebabkan karena adanya noise, maka penyinaran berulang terhadap pasien bisa terjadi, dan akibatnya pasien akan mendapatkan dosis radiasi berlebih, hal inilah yang menyebabkan penelitian ini perlu untuk dilakukan agar citra yang dihasilkan dalam keadaan baik sehingga bagian tubuh yang menjadi objek pemeriksaan dapat didiagnosis dengan baik.

\section{METODE}

Penelitian dilakukan di Instalasi Radiologi Rumah Sakit Stroke Nasional (RSSN) Bukittinggi dan Laboratorium Nuklir Jurusan Fisika UNAND. Alat yang digunakan pada penelitian ini adalah pesawat CT-Scan dan satu unit komputer, sedangkan bahan yang digunakan adalah fantom sebagai bahan pengganti pasien.

\subsection{Pengambilan Data}

Langkah awal penelitian yaitu pengambilan citra fantom yang dihasilkan oleh pesawat CT-Scan CT99 GE (General Electric) Elite 16 Slice. Pengambilan citra dilakukan pada nilai arus $250 \mathrm{mAs}$, tegangan $120 \mathrm{kV}$, variasi slice thickness $1 \mathrm{~mm}-10 \mathrm{~mm}$, serta rekonstruksi kernel yang digunakan adalah standar, lung, soft, edge, bone dan chest. Sebelum dilakukan pengambilan citra, posisi fantom diatur ditengah gantry, arus, tegangan dan slice thickness yang digunakan diatur sebelum dilakukan proses scanning. Citra fantom yang dihasilkan direkonstruksi dengan semua jenis variasi kernel yang digunakan dan dipotong sesuai dengan keinginan.

\subsection{Pengolahan Data}

Nilai standar deviasi dari citra yang dihasilkan dibaca pada daerah ROI dengan menggunakan software Java. Nilai noise dapat ditentukan dari nilai selisih standar deviasi ROI maksimum dengan ROI minimum. Jika scanning tidak dilakukan pada parameter $12 \mathrm{O}$ kV, 300 
mAs, dan tebal slice $8 \mathrm{~mm}$, maka konversikan setiap nilai noise di keempat tepinya dengan menggunakan Persamaan (1).

$$
S s=S m \frac{k V}{120} \sqrt{\frac{m A s x \text { Slicewidth }}{300 x 8}}
$$

Ss adalah nilai noise terkoreksi, $S m$ adalah nilai noise hasil pengukuran, $k V$ adalah nilai tegangan setting, mAs adalah kuat arus setting, dan Slicewidth dalah tebal slice setting. Nilai standar deviasi dihitung pada citra dengan cara memilih Region of Interest (ROI) untuk lima titik, yaitu satu titik pada posisi pusat (tengah) dan 4 titik lainnya yaitu pada arah jam 12 (atas), jam 3 (kanan), jam 6 (bawah) dan jam 9 (kiri) seperti pada Gambar 1.

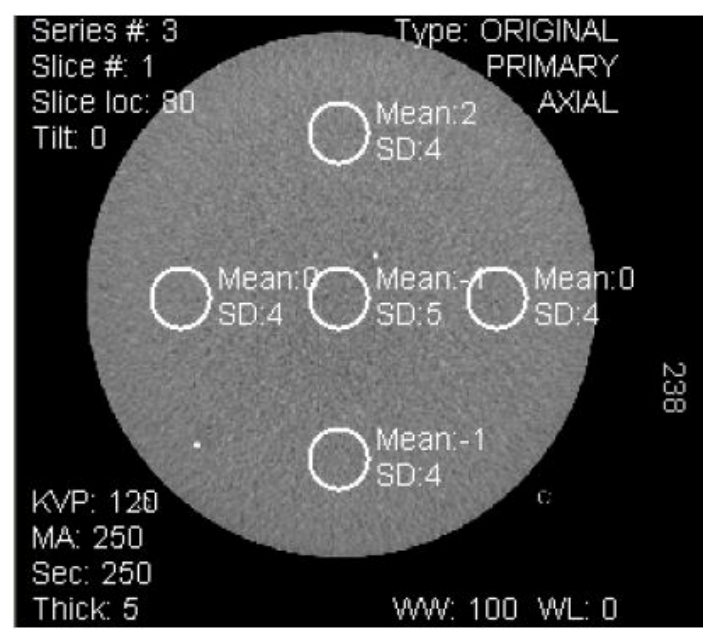

Gambar 1 Uji cross field uniformity CT Number dengan ROI

\section{HASIL DAN DISKUSI}

\subsection{Pengaruh Rekonstruksi Kernel dengan Variasi Slice Thickness terhadap Nilai Noise}

Hasil pengukuran nilai noise dapat dilihat pada Gambar 2. Nilai noise yang didapatkan memenuhi standar perka BAPETEN No.2 tahun 2018 yaitu $\leq 2 \mathrm{HU}$, hal ini berlaku untuk semua jenis rekonstruksi kernel yang digunakan.

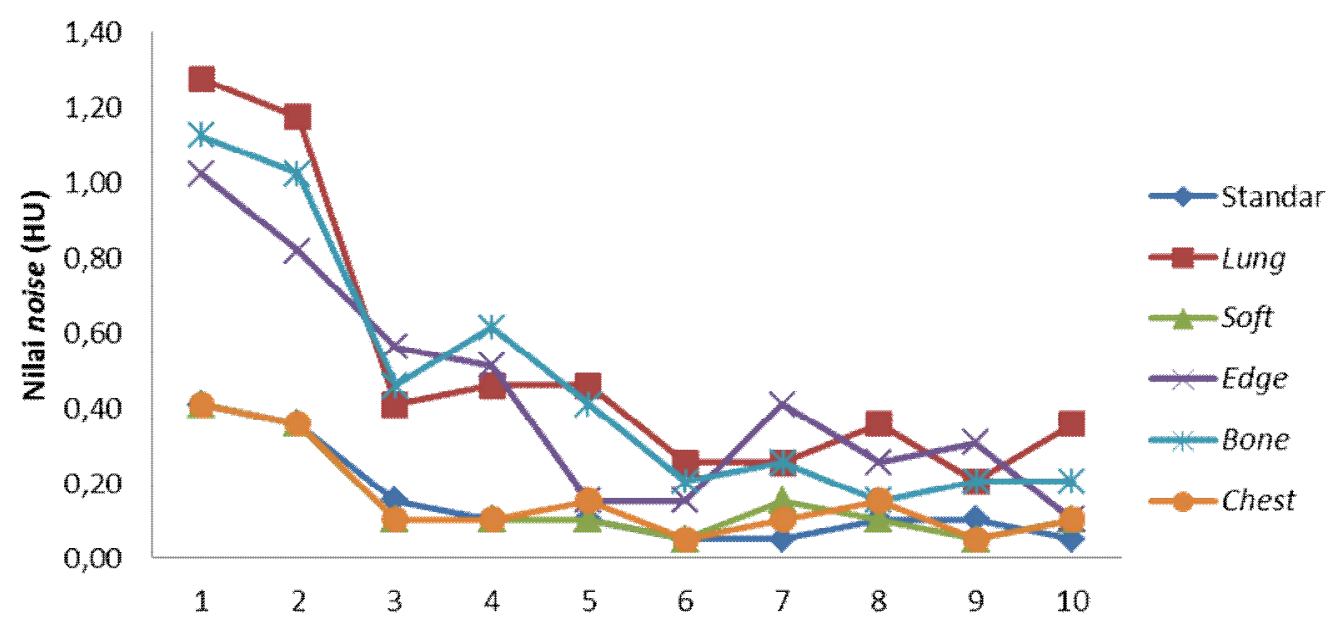

Gambar 2 Grafik perbandingan nilai noise pada rekonstruksi dengan variasi slice thickness 
Noise bisa terbentuk karena dipengaruhi oleh jumlah energi foton yang ditangkap oleh detektor, ketika foton yang ditangkap oleh detektor banyak maka sinyal detektor yang dihasilkan kuat, hal ini mengakibatkan sedikit noise yang dihasilkan. Namun, ketika foton yang ditangkap oleh detektor sedikit, maka sinyal detektor yang dihasilkan lemah sehingga akan mengakibatkan lebih banyak noise yang dihasilkan. Noise bisa dikurangi dengan melakukan kalibrasi secara teratur. Evaluasi noise sebaiknya dilakukan setiap hari sebagai salah satu upaya untuk mengurangi noise pada citra yang dihasilkan oleh pesawat CT-Scan (Seeram, 2016).

\subsection{Pengaruh Rekonstruksi Kernel dan Slice Thickness terhadap Nilai Noise}

Nilai noise yang didapatkan berbeda dengan setiap variasi rekonstruksi yang digunakan (Gambar 2). Nilai noise yang terbentuk setelah citra direkonstruksi dipengaruhi oleh kepadatan frekuensi rekonstruksi yang digunakan, rekonstruksi digunakan untuk memperbaiki resolusi kontras suatu citra. Kepadatan Frekuensi rekonstruksi yang tinggi dapat meningkatkan resolusi kontras suatu citra, namun terdapat banyak noise. Noise dapat dikurangi dengan penggunaan kepadatan frekuensi rekonstruksi yang rendah untuk jaringan yang lembut atau jaringan yang memiliki kontras subjek yang mudah untuk dibedakan (Mayo,1991).

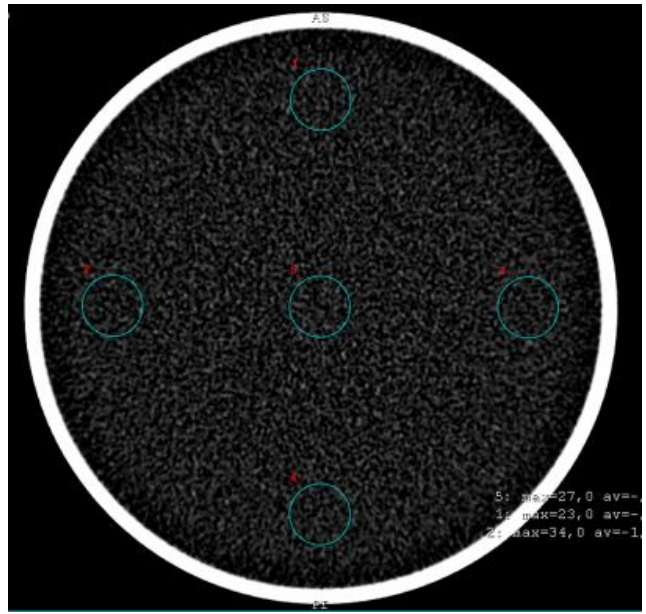

(a)

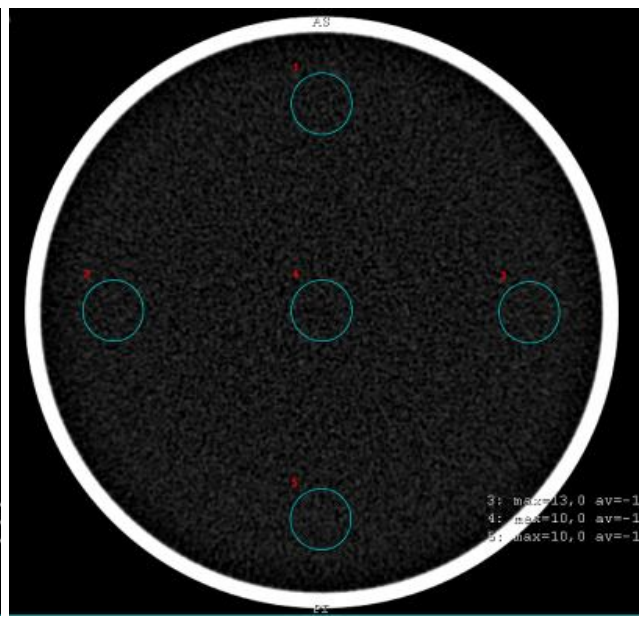

(b)

Gambar 3 Hasil citra yang menunjukan perbandingan nilai noise pada rekonstruksi standar (a)Slice thickness $1 \mathrm{~mm}$ (b)Slice thickness $6 \mathrm{~mm}$

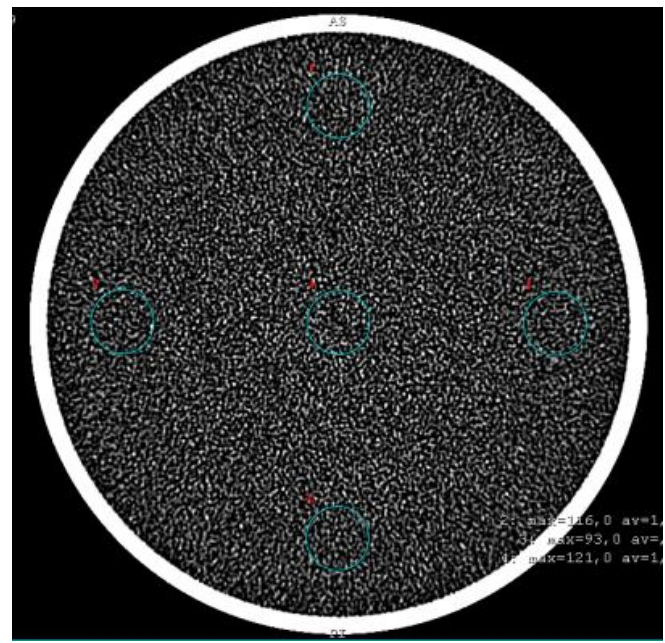

(a)

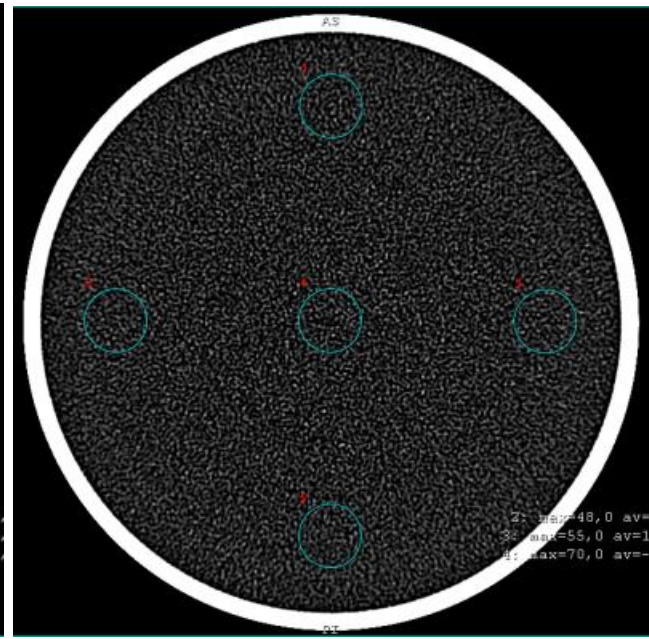

(b)

Gambar 4 Hasil citra yang menunjukan perbandingan nilai noise pada rekonstruksi lung

(a)Slice thickness $1 \mathrm{~mm}$ (b)Slice thickness $6 \mathrm{~mm}$ 


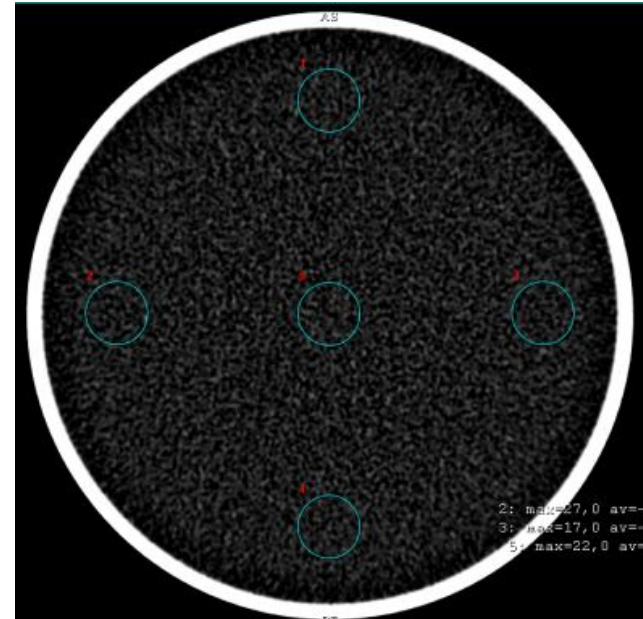

(a)

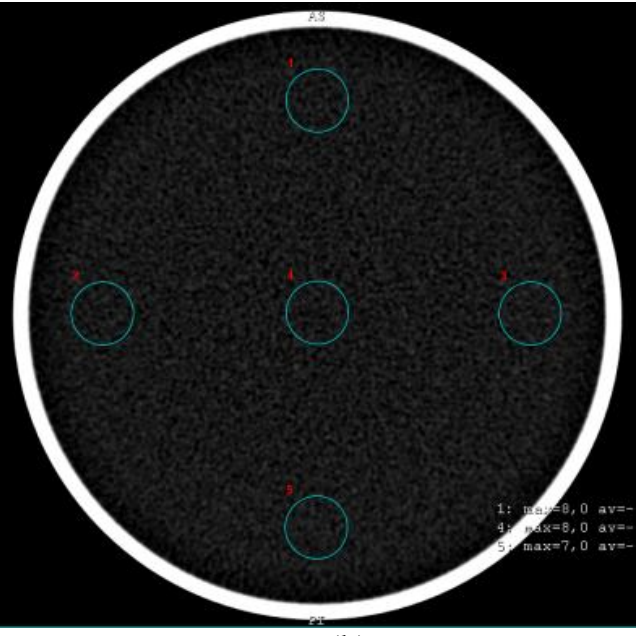

(b)

Gambar 5 Hasil citra yang menunjukan perbandingan nilai noise pada rekonstruksi soft (a)Slice thickness $1 \mathrm{~mm}$ (b)Slice thickness $6 \mathrm{~mm}$

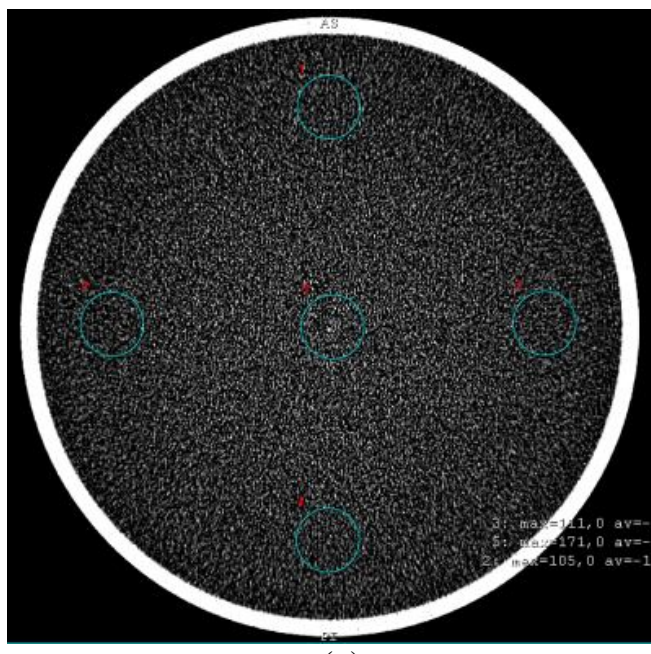

(a)

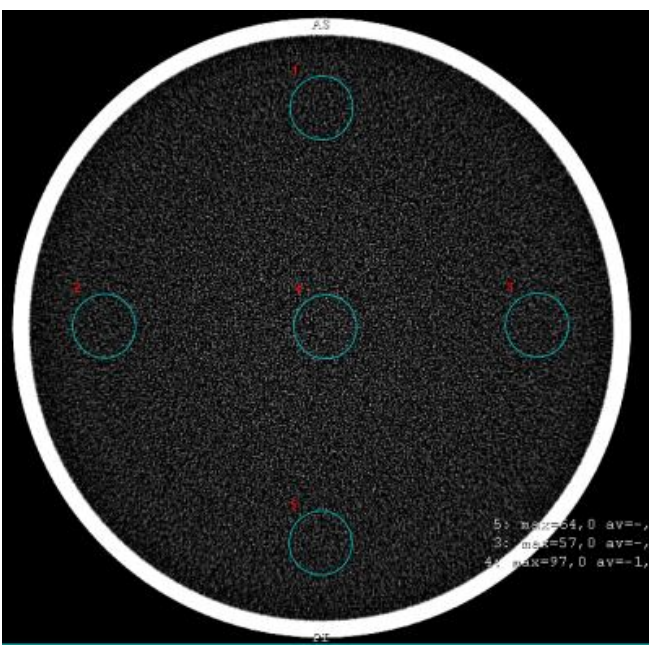

(b)

Gambar 6 Hasil citra yang menunjukan perbandingan nilai noise pada rekonstruksi edge (a)Slice thickness $1 \mathrm{~mm}$ (b)Slice thickness $6 \mathrm{~mm}$

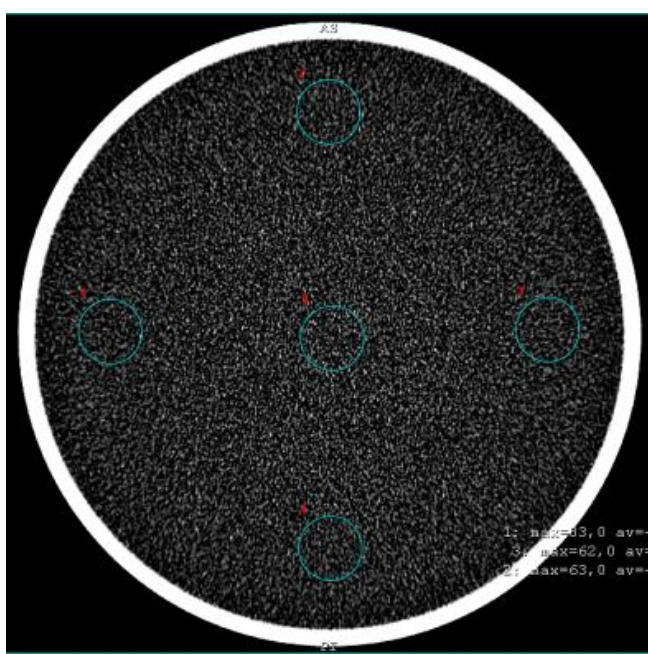

(a)

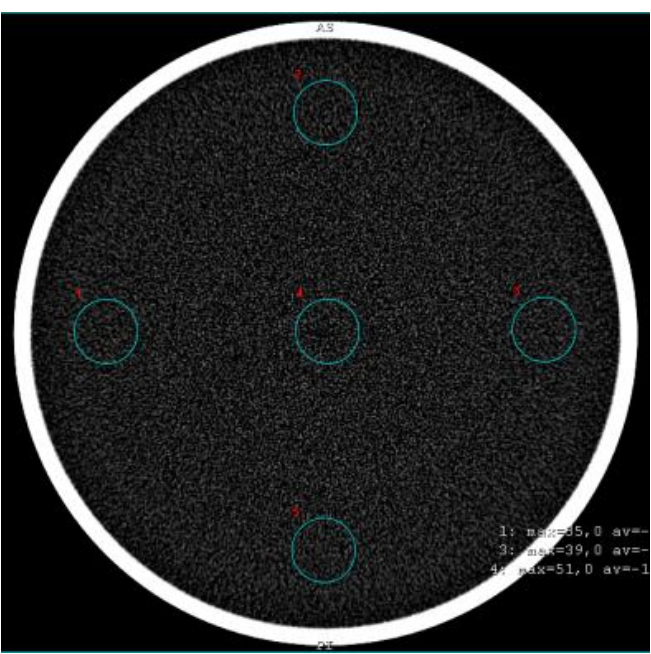

(b)

Gambar 7 Hasil citra yang menunjukan perbandingan nilai noise pada rekonstruksi bone (a) Slice thickness $1 \mathrm{~mm}$ (b)Slice thickness $6 \mathrm{~mm}$ 


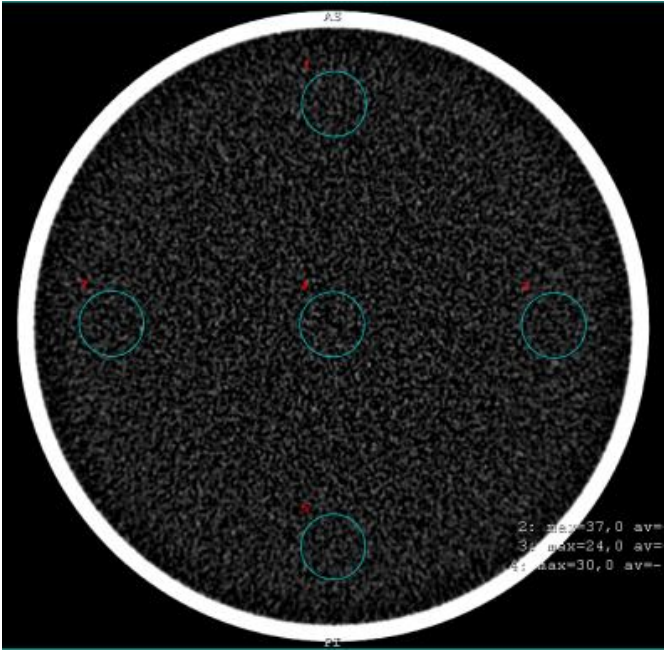

(a)

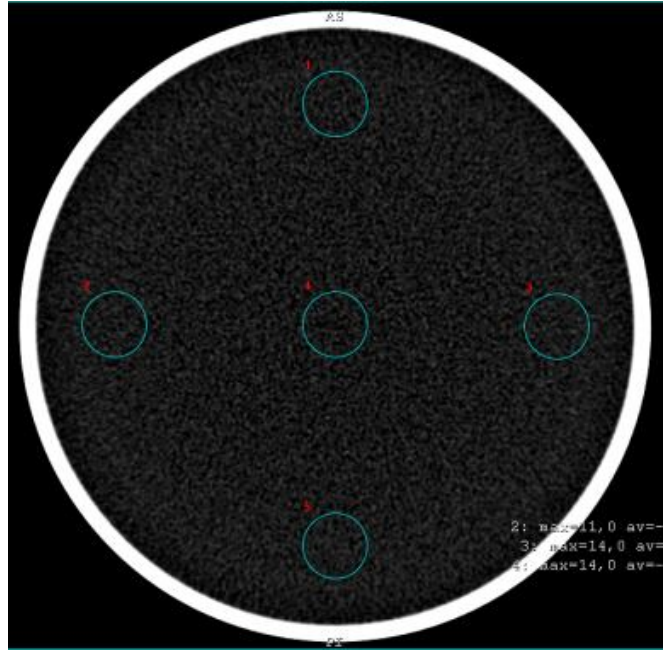

(b)

Gambar 8 Hasil citra yang menunjukan perbandingan nilai noise pada rekonstruksi chest (a)Slice thickness $1 \mathrm{~mm}$ (b)Slice thickness $6 \mathrm{~mm}$

Kualitas citra yang terbaik diperoleh pada rata-rata penggunaan slice thickness yaitu dengan ketebalan $6 \mathrm{~mm}$, karena pada ketebalan tersebut didapatkan nilai noise yang paling sedikit (Gambar 3-8). Penggunaan slice thickness yang tidak terlalu tebal akan menghasilkan citra dengan detail-detail gambar yang tinggi, sedangkan penggunaan slice thickness yang tebal akan menghasilkan citra dengan detail gambar yang rendah. Besar kecilnya ukuran slice thickness yang digunakan bergantung pada kebutuhan diagnosis dari objek yang diperiksa. Penggunaan tegangan, arus, slice thickness dan hal-hal lainya yang mempengaruhi nilai noise perlu dioptimalkan agar nilai noise yang terbentuk pada saat rekonstruksi bisa berkurang sehingga bagian tubuh yang menjadi objek pemeriksaan dapat didiagnosis dengan baik.

\section{KESIMPULAN}

Berdasarkan hasil pengukuran standar deviasi pada hasil citra yang dihasilkan oleh pesawat CT-Scan, diperoleh beberapa kesimpulan yaitu bahwa nilai noise yang didapatkan untuk semua rekonsrtuksi kernel yang digunakan masih dalam batas toleransi perka BAPETEN No.2 tahun 2018 tentang uji kesesuaian pesawat sinar-X radiologi diagnostik dan intervensional. Nilai noise pada citra pesawat CT-Scan yang telah direkonstruksi mengalami peningkatan yang dipengaruhi oleh kepadatan frekuensi reknstruksi yang digunakan. Slice thickness dengan ketebalan $6 \mathrm{~mm}$ menghasilkan nilai noise yang paling kecil dengan detail gambar yang baik, hal ini berlaku untuk hampir semua jenis rekonstruksi kernel.

\section{DAFTAR PUSTAKA}

Akhadi, M., "Dasar-Dasar Proteksi Radiasi” (PT.Renika Cipta, Jakarta, 2000), hal 32-37.

Anam, C, "Reduksi Noise Pada Citra CT-Scan Hasil Rekonstruksi Metode Filtered BackProjection (Fbp) Menggunakan Filter Wiener Dan Median", Prosiding Seminar Nasional Keselamatan Kesehatan dan Lingkungan dan Pengembangan Teknologi Nuklir, Institut Teknologi Bandung, 2015.

American Assosiation of Physicists in Medicine (AAPM), "Quality Control in Diagnostic Radiology", AAPM Report 74, USA, 2002.

American Assosiation of Physicists in Medicine (AAPM), "Spesification and Acceptance Testing of Computed Tomography Scanners", AAPM Report 39, USA, 2013.

Hediana, "Penentuan Nilai Noise Berdasarkan Slice Thickness pada Citra CT-Scan, Fakultas Matematika dan Ilmu Pengetahuan Alam", Skripsi S1, Universitas Sumatera Utara, Medan, 2015.

Mayo, J.R., "High Resolution Computed Tomography Technical Aspects" (Radiologic Clinic of North America, Columbia, 1991), Hal 1042-1048. 
Seeram, E, "Computed Tomograpgy Physical Principles, Clinical Applications, and Quality Control", Fourth Edition, (W.B. Saunders Company, Philadelphia, 2016), hal 26-29

Peraturan Kepala BAPETEN Nomor 2 Tahun 2018 Tentang UJi Kesesuaian Pesawat Sinar-X Radiologi Diagnostik dan Intervensional, https://jdih.bapeten.go.id/files/_000225_1.pdf, diakses April 2018 